\title{
Evaluation of pyriproxyfen, a juvenile hormone analog, on Drosophila melanogaster (Diptera: Drosophilidae): Insecticidal activity, ecdysteroid contents and cuticle formation
}

\author{
Fethi BENSEBAA, SAmira KILANI-MORAKCHI, NAdia ARIBI and Noureddine SOLTANI
}

\begin{abstract}
Laboratory of Applied Animal Biology, Department of Biology, Faculty of Sciences, Badji Mokhtar University of Annaba, 23000-Annaba, Algeria; e-mails: fethi.bensebaa@gmail.com; samira.morakchi@univ-annaba.dz; nadia.aribi@univ-annaba.dz; noureddine.soltani@univ-annaba.dz
\end{abstract}

Key words. Diptera, Drosophilidae, pyriproxyfen, Drosophila melanogaster, toxicity, ecdysteroids, cuticle, chitin

\begin{abstract}
The efficacy of pyriproxyfen, a juvenile hormone analog (JHA), was evaluated using third instar larvae of Drosophila melanogaster Meigen, 1830 (Diptera: Drosophilidae). Various doses of the compound, ranging from 0.01 to 2 ng/larva, were applied topically to larvae ( $12 \mathrm{~h}$ before pupariation). Treatment did not prevent pupariation but inhibited adult emergence at all the doses tested. In a second series of experiments the ecdysteroid content of pupae was determined following application of pyriproxyfen at two doses, 0.108 and $0.29 \mathrm{ng} /$ larva, corresponding to $\mathrm{ID}_{25}$ and $\mathrm{ID}_{50}$, the doses required for 25 and $50 \%$ inhibition of adult emergence, respectively. Pyriproxyfen treatment increased the duration of pupal development. In addition, enzyme immunoassay measurements of ecdysteroids in whole body extracts of pupae indicated that pyriproxyfen decreased the ecdysteroid content in a dose-dependent manner. Finally, the effects on the cuticle of pyriproxyfen $\left(\mathrm{ID}_{50}\right)$ were studied histologically, which revealed that this compound increased the thickness of the new adult cuticle and suppressed the formation of bristles. Biochemical analyzes revealed that an increase in chitin content of the cuticle is only recorded at the highest dose. Thus, a topical application of pyriproxyfen to third instar larvae interfered with the molting hormone and disrupted the normal development of this insect.
\end{abstract}

\section{INTRODUCTION}

In insects 20-hydroxyecdysone (20E) and juvenile hormone $(\mathrm{JH})$, play a central role in the regulation of growth and development (Nijhout, 1994). According to the classical dogma of insect endocrinology, the balance of these two hormones defines the outcome of each developmental transition (Dubrovsky, 2005). 20E initiates all major developmental transitions, but it is an interaction with $\mathrm{JH}$ that transduces the 20E pulses into stage-specific responses (Dubrovsky, 2005). Indeed, JH has been shown to modulate the action of ecdysteroids in various insects (Nijhout, 1994; Riddiford, 1996). There is little literature on the physiological and biochemical processes related to molting and metamorphosis in insects compared to other aspects, like reproduction (De Loof et al., 2015).

Recent advances in understanding the mechanism that regulate molting and metamorphosis in insects have relied heavily on using Drosophila melanogaster as a model system. However, the effect of JH on $20 \mathrm{E}$ and the cross-talk between these two hormones is not well established (Quinn et al., 2012; Yamanaka et al., 2013). In addition to its wellknown advantages for molecular and genetic studies, $D$. melanogaster provides an ideal model system for elucidating the mechanisms of hormones, since $20 \mathrm{E}$ appears to be responsible for directing the major developmental transitions in the life cycle of this insect, including molting and metamorphosis (Quinn et al., 2012).

As recorded for ecdysone agonists and juvenile hormone analogs, interference with hormonal balance leads to inter- rupted development and are potential specific targets for use in pest control (Penner \& Dhadialla, 2012). However, a better and complete understanding of regulatory processes underlying insect development still imperative for their rational management. Furthermore, JHAs are also excellent tools for studying endocrinological mechanisms in insects (Ramaseshadri et al., 2012).

The insect growth regulator (IGR), pyriproxyfen, is a JHA with a relatively low mammalian toxicity (Miyamoto et al., 1993). It is a broad-spectrum insect growth regulator with insecticidal activity against agricultural, horticultural and public health insect pests (Who, 2008), and has been successfully used to control important pests of many agricultural crops all over the world (Sazo et al., 2008; Moadeli et al., 2014). Pyriproxyfen, the most potent JHA available today (Hatakoshi, 2012), inhibits metamorphosis and embryogenesis in several insect orders, including Diptera (Kawada et al., 1988; Ishaaya et al., 1994; Aribi et al., 2006). In addition, this compound suppresses oviposition, reduces viability of eggs (Ghasemi et al., 2010; Ohba et al., 2013) and reduces fecundity (Singh \& Kumar, 2015). Recently, pyriproxyfen was reported to affect some physical and biochemical processes in insects, such as moulting, by influencing the activity of chitinases (Nasr et al., 2010).

Therefore, in the present study we investigated the effect of pyriproxyfen on D. melanogaster in order to better understand the interaction between the two principal hormones, JH and 20E. Pyriproxyfen was applied topically to larvae at the end of third instar, when the $\mathrm{JH}$ titer drops to 
an undetectable level to allow the molting hormone (ecdysteroids) to initiate metamorphosis, in order to firstly determine its insecticidal potency, and then its effects on pupal development, the ecdysteroid profile and the chitin content and structure of the new cuticle, respectively.

\section{MATERIAL AND METHODS}

\section{Insects}

Canton-S wild-type flies of D. melanogaster, a widely used laboratory strain, were reared in glass vials containing a yeast/ cornmeal/agar laboratory medium containing an anti-fungal agent, which were kept in a breeding room at $25 \pm 2{ }^{\circ} \mathrm{C}$ and $70 \%$ humidity under a 12L : $12 \mathrm{D}$ cycle.

\section{Treatment and bioassay}

Pyriproxyfen ( $>95 \%$, Sumitomo Chemical Company. Ltd., Osaka, Japan) was dissolved in acetone and topically applied $(1 \mu \mathrm{l} / \mathrm{insect})$ to third instar larvae of D. melanogaster $(12 \mathrm{~h}$ before pupariation when the JH titer drop to an undetectable level). Control insects were treated with $1 \mu \mathrm{l}$ acetone alone.

This compound was tested at five doses $(0.01,0.1,0.5,1$ and $2 \mathrm{ng} /$ larva) and the percentage inhibition of adult emergence was recorded. For each dose, three replicates of 20 insects were used. The percentage inhibition was corrected following Abbott (1925). The $\mathrm{ID}_{50}$ and $\mathrm{ID}_{25}$ (doses that caused an inhibition in adult emergence of $50 \%$ and $25 \%$, respectively) were determined together with the corresponding 95\% fiducial limits (95\% FL) and the Hill slope.

\section{Duration of pupal development}

The duration of the pupal period was recorded for control and treated $\left(\mathrm{ID}_{50}, \mathrm{ID}_{25}\right)$ insects. Pupae were observed at $4 \mathrm{~h}$ intervals until adult emergence. There were seven to eight replicates, each consisting of 20 insects.

\section{Enzyme immunoassay of ecdysteroids}

Third-instar larvae were treated as above with two doses $\left(\mathrm{ID}_{50}\right.$ and $\mathrm{ID}_{25}$ ) and surviving pupae were sampled at various times during pupal development $(12,36,48,60$ and $84 \mathrm{~h}$ after puparium formation (APF)). Samples were extracted individually with methanol by sonication (2-3 min). After centrifugation (5000 g, $10 \mathrm{~min})$, the supernatants were taken and evaporated $\left(60^{\circ} \mathrm{C}\right)$ Each body extract was resuspended in $500 \mu \mathrm{l}$ of phosphate buffer $(0.1 \mathrm{M} ; \mathrm{pH} 7.4)$ and analyzed using an enzyme immunoassay (EIA) as previously described (Aribi et al., 2006) using rabbit polyclonal B antibody against $20 \mathrm{E}$, peroxidase as an enzymatic tracer and tetramethyl benzidine as a colouring agent. Data are expressed in pg 20E equivalents per mg of body weight. Antibody was kindly supplied by J.P. Delbecque (CNRS, Université de Bordeaux I, France) and peroxidase by C. Blaise (Pierre and Marie Curie University, Paris, France).

\section{Chitin quantification}

Chitin quantification of a whole pupa was performed as previously described (Farnesi et al., 2012). Chitin content of pupae sampled at various ages $(12,36,48,60$ and $84 \mathrm{~h}$ APF) was evaluated by quantification of glucosamine derivatives obtained by deacetylation, depolymerisation and deamination of $\mathrm{N}$-acetylglucosamine polymer. Chitin undergoes an alkaline digestion with $\mathrm{KOH}(14 \mathrm{M})$ at $130^{\circ} \mathrm{C}$ in order to deacetylate the chitin, thus forming chitosan. A solubilized chitosan solution is then depolymerized using $\mathrm{NaNO}_{2}(10 \%)$ and $\mathrm{KHSO}_{4}(10 \%)$ in order to release the amine residues from the glucosamine, forming a soluble aldehyde. The aldehydes generated in a reaction with $\mathrm{HNO}_{2}$ and with the further addition of MBTH and $\mathrm{Fe}^{+3}$ develop a blue col- oration. Absorbance was read at $650 \mathrm{~nm}$ and chitin content was expressed as glucosamine equivalents, according to a standard curve of glucosamine $(50-1000 \mu \mathrm{g})$. Before chitin quantification, the weight of the pupae was determined to normalize the results.

\section{Histology}

Histological procedures were performed following Martoja \& Martoja (1967). Pupae (60 and 84 h APF, these ages were chosen because adult cuticle deposition begins between 48 and $53 \mathrm{~h}$ APF) that developed, from pyriproxyfen-exposed or control larvae were fixed in $10 \%$ formol. After dehydration in a series of graded ethanol the samples were passed through three washes in xylene before being embedded in paraffin wax. Transverse sections of the abdomen ( $4 \mu \mathrm{m})$ obtained using a Leica RM2125T (Leica Microsystems Nussloch GmbH, Wetzlar, Germany) manual rotary microtome, were stained with hematoxylin-Eosin. The abdominal region was chosen because JHA causes the development of abnormalities in this region (Zhou \& Riddiford, 2002). Observations were made using a Leica DM500 microscope equipped with a Leica ICC50 HD camera and the thickness of the cuticle, based on five measurements, was determined using Las EZ Leica software.

\section{Statistical analysis}

Results are given as means \pm standard errors (SE). Data for the toxicity were analyzed using non-linear sigmoid curve fitting, and the activity of the treatment was evaluated in terms of a dose dependent response. The goodness of fit to the curve was evaluated on the basis of $\mathrm{R}^{2}$ values. The homogeneity of variances was checked using Bartlett's and Brown-Forsythe tests. Data on pupal duration, EIA measurement and chitin quantification were subjected to one-way or two-way analysis of variance (ANOVA) followed by a post-hoc HSD Tukey test. The cuticle measurements were assessed using a Mann-Whitney test. All statistical analyses were performed using Prism v 6.01 for Windows (GraphPad Software Inc., www.graphpad.com).

\section{RESULTS}

\section{Insecticidal activity}

Pyriproxyfen applied topically to third instar larvae of D. melanogaster inhibits adult emergence in a dose dependent way. Partial adult emergence and malformed adults were also classified as dead, since treatment does not prevent pupariation. The corrected inhibition percentages ranged from $8.12 \pm 1.55 \%$ at lowest dose $(0.01 \mathrm{ng})$ up to a maximum of $89.69 \pm 1.47 \%$ at the highest dose (2 $\mathrm{ng})$ (Fig. 1). The percentage inhibition recorded in controls was $11.66 \pm 1.66 \%$. The $\mathrm{ID}_{50}$ and $\mathrm{ID}_{25}$ values together with their corresponding $95 \%$ fiducial limits $(95 \%$ FL) are given in Table 1.

TABLE 1 . Toxicity of pyriproxyfen applied topically to larvae of $D$. melanogaster at the end of the third instar. The data are expressed in terms of inhibiting dose (ID) of adult emergence together with the corresponding 95\% fiducial limits (95\%FL). $\mathrm{R}^{2}$ - coefficient of determination.

\begin{tabular}{lccc}
\hline Doses & Value (ng) & Fiducial limits (95\%) & $\mathrm{R}^{2}$ \\
\hline $\mathrm{ID}_{50}$ & 0.29 & {$[0.21-0.39]$} & \\
$\mathrm{ID}_{25}$ & 0.108 & {$[0.06-0.17]$} & 0.99 \\
Hill slope & 1.11 & {$[0.78-1.43]$} & \\
\hline
\end{tabular}




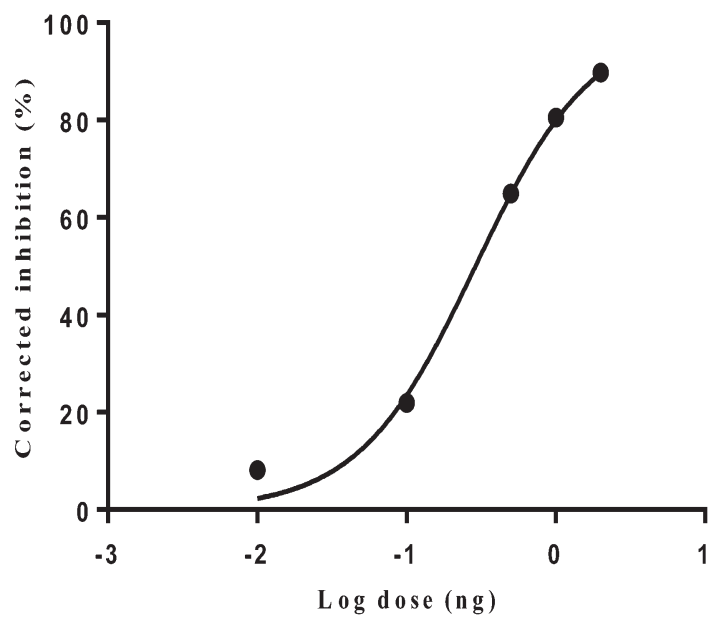

Fig. 1. Effect of pyriproxyfen, topically applied to larvae of D. melanogaster at the end of the third instar: sigmoidal dosedependent response curve of corrected inhibitions (\%) of adult emergence as a function of the logarithm of the doses.

\section{Effect on the duration of pupal development}

The duration of pupal development is given in Fig. 2. Treatment of third instar larvae increased the duration of pupal development only at the highest dose $\operatorname{ID}_{50}(0.29 \mathrm{ng})$ $\left(\mathrm{F}_{2,20}=8.543 ; \mathrm{p}=0.0021\right)$. The means values recorded were $88.25 \pm 3.01 \mathrm{~h}$ for the control and $102.57 \pm 1.71 \mathrm{~h}$ for the $\left(\mathrm{ID}_{50}\right)$ treated pupae. Thus, pyriproxyfen delayed adult emergence by approximately $14 \mathrm{~h}$.

\section{Effect on the ecdysteroid content}

During pupal development the ecdysteroid titer in the control series increased from $264.89 \pm 7.68 \mathrm{pg} 20 \mathrm{E} / \mathrm{mg}$ at $12 \mathrm{~h} \mathrm{APF}$ to reach a peak of $414.24 \pm 2.71 \mathrm{pg} 20 \mathrm{E} / \mathrm{mg}$ at $36 \mathrm{~h} \mathrm{APF}$ and then decreased $(\mathrm{p}<0.0001)$ (Fig. 3). In the treated series, a similar trend was recorded for the two doses tested ( $\mathrm{ID}_{25}$ and $\mathrm{ID}_{50}$ ). However, ecdysteroid titer remained stable after $60 \mathrm{~h}$ in the $\mathrm{ID}_{25}$ and after $48 \mathrm{~h}$ in the $\mathrm{ID}_{50}$ treatments. EIA measurements revealed that the two doses tested caused significant reductions in the ecdysteroid titers $(\mathrm{p}<0.0001)$ at $12 \mathrm{~h}$ and $36 \mathrm{~h} \mathrm{APF}$. Moreover,

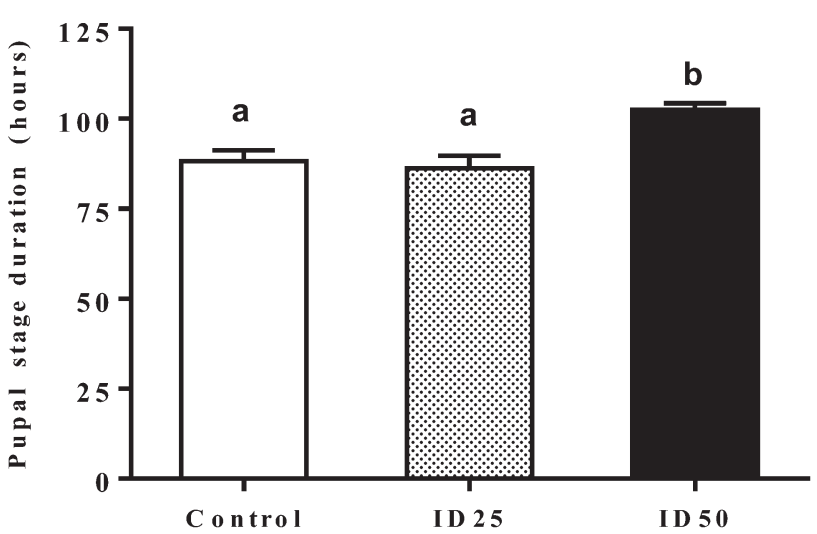

Fig. 2. Effect of pyriproxyfen, topically applied to larvae of $D$. melanogaster at the end of the third instar, on the duration of the pupal stage $(\mathrm{h})(\mathrm{m} \pm \mathrm{SE} ; \mathrm{n}=7-8$ replicates, each of 20 insects). Different letters indicate a significant difference $(p<0.05)$.

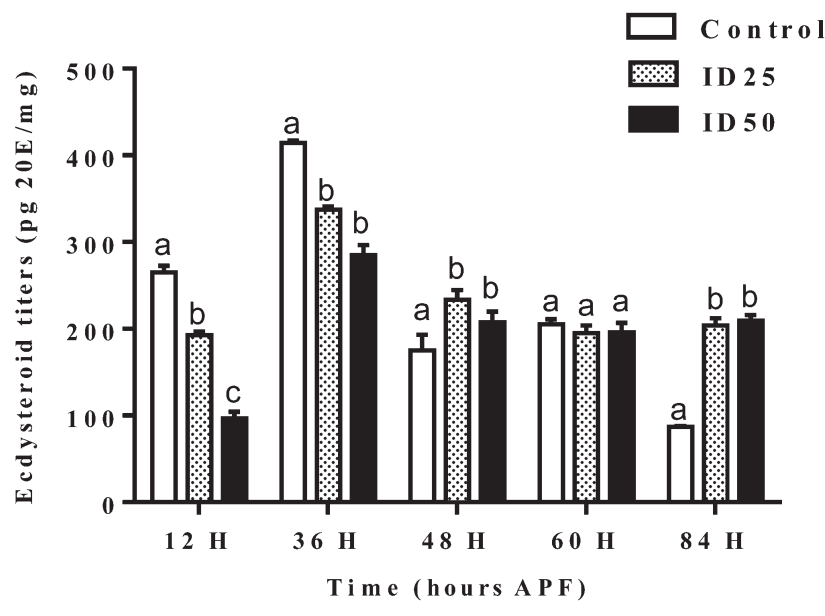

Fig. 3. Effect of pyriproxyfen $\left(\mathrm{ID}_{25}, \mathrm{ID}_{50}\right)$, topically applied to larvae of $D$. melanogaster at the end of the third instar, on the ecdysteroid (pg 20E/mg of weight) titer during pupal development $(\mathrm{m} \pm \mathrm{SE} ; \mathrm{n}=3-5)$. Mean values for individuals of the same age followed by different letters are significantly different $(\mathrm{p}<0.05)$.

an increase in ecdysteroids titer was recorded at $84 \mathrm{~h}$ in the treated series because the values recorded between 60 and $84 \mathrm{~h}$ remained stable in the treated series but decreased after $60 \mathrm{~h}$ in the controls. ANOVA revealed significant effects of dose $\left(\mathrm{F}_{2,36}=22.25 ; \mathrm{p}<0.0001\right)$, time $\left(\mathrm{F}_{4,36}=205\right.$; $\mathrm{p}<0.0001)$ and the dose-time interaction $\left(\mathrm{F}_{8,36}=51.92 ; \mathrm{p}\right.$ $<0.0001)$.

\section{Effect on chitin content}

As shown in Fig. 4, the whole body chitin content of the controls increased during pupal development $(36,48 \mathrm{~h}$ APF) and then decreased ( $<<0.0001)(60$ and 84 h). Generally, the trend in the chitin content of the treated series is similar to that in the control and appears to be correlated with the ecdysteroid titers (Fig. 3). Pyriproxyfen treatment resulted in a significant $(p<0.0001)$ increase in the chitin content compared to the control only at the highest dose $\left(\mathrm{ID}_{50}\right)$. ANOVA revealed a significant effect of dose $\left(\mathrm{F}_{2,119}\right.$

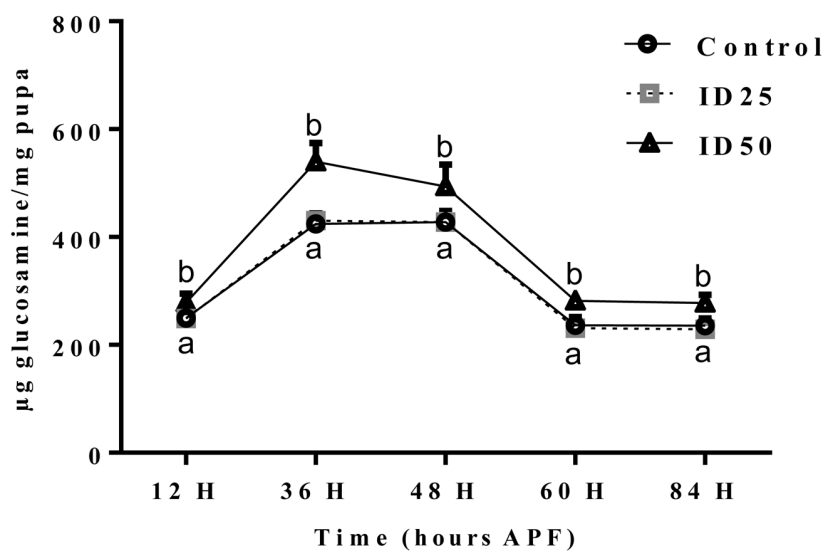

Fig. 4. Effect of pyriproxyfen $\left(\mathrm{ID}_{25}, \mathrm{ID}_{50}\right)$, topically applied to larvae of $D$. melanogaster at the end of the third instar, on the chitin content ( $\mu \mathrm{g}$ of glucosamine/mg) during pupal development $(\mathrm{m} \pm \mathrm{SE} ; \mathrm{n}=8-11)$. Mean values for individuals of the same age followed by different letters are significantly different $(\mathrm{p}<0.05)$. 


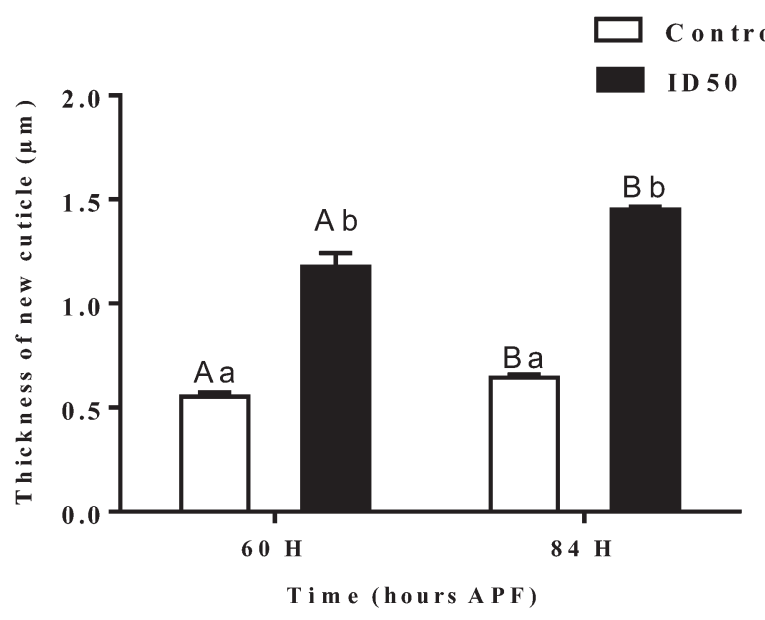

Fig. 5. Effect of pyriproxyfen $\left(\mathrm{ID}_{50}\right)$, topically applied to larvae of $D$. melanogaster at the end of the third instar, on cuticle thickness $(\mu \mathrm{m})(\mathrm{m} \pm \mathrm{SE} ; \mathrm{n}=5)$. Different capital letters indicate a significant difference between individuals of the same age in the same series; different small letters indicate a significant difference between control and treated individuals of the same age $(\mathrm{p}<0.05)$.

$=108.2 ; \mathrm{p}<0.0001)$, time $\left(\mathrm{F}_{4,119}=700 ; \mathrm{p}<0.0001\right)$ and the

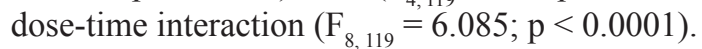

\section{Structure of new cuticle}

As shown in Fig. 5 the thickness of new cuticle in the control series was $0.552 \pm 0.021 \mu \mathrm{m}$ at $60 \mathrm{~h} \mathrm{APF}$ and increased to a maximum of $0.645 \pm 0.013 \mu \mathrm{m}$ at $84 \mathrm{~h} \mathrm{APF} \mathrm{(p}$ $<0.01)$. Pyriproxyfen $\left(\mathrm{ID}_{50}\right)$ treatment caused a significant increase in the thickness of the cuticle $(p<0.01)$ recorded at 60 and $84 \mathrm{~h} \mathrm{APF}$. Moreover, the increase in cuticle thickness in the treated series $\left(\mathrm{ID}_{50}\right)$ is much greater whatever the age (mean percentage of $45 \%$ ) compared to the standard increase with age in the control series, which is $14.41 \%$. As shown in Fig. 6, the new adult cuticle in the control series has normal bristles (Fig. 6A), but lacks bristles in treated series (Fig. 6B).

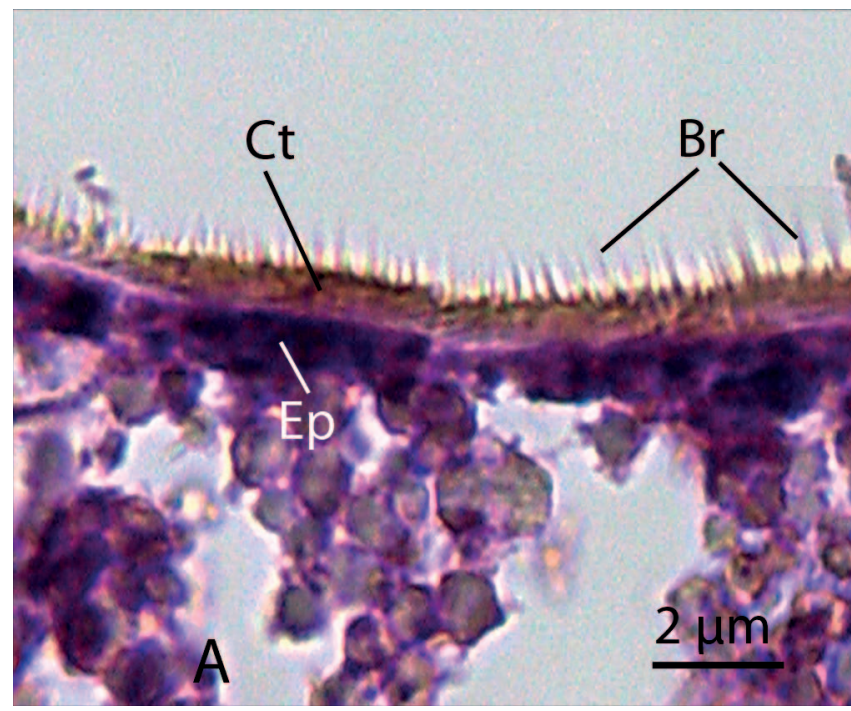

\section{DISCUSSION}

In the present study we topically applied a juvenile hormone analog, pyriproxyfen, to third instar larvae of $D$. melanogaster just prior to pupariation. This did not kill the larvae or prevent them from pupating but did result in a dose-dependent inhibition of adult emergence and caused morphological abnormalities in the adults that did emerge. Zhou \& Riddiford (2008) report that unlike Lepidoptera and most other holometabolous insects, higher Diptera, such as D. melanogaster, have lost most of their sensitivity to JH. Indeed, topical applications of JH or JHA do not prevent $D$. melanogaster larvae pupating and have no role in initiating metamorphosis (Riddiford et al., 2003). Furthermore, in Drosophila and other higher flies, the pupa is derived from imaginal discs, except for the abdominal cuticle, which is produced by persisting larval epidermal cells and histoblasts, which may account for the inability of JH or JHA to prevent the larval-pupal transformation (Zhou \& Riddiford, 2002). Nevertheless, applications of JH or JHA before or at the time of pupation prevent normal adult development (Zhou \& Riddiford, 2002).

Pyriproxyfen is known to be a potent inhibitor of metamorphosis and adult development. Indeed, Boina et al. (2009) report that the topical application of pyriproxyfen suppress adult emergence in the Asian citrus psyllid. Pyriproxyfen also inhibits the emergence of Aedes aegypti (Sihuincha et al., 2005; Harburger et al., 2011), Anopheles culicifacies, Anopheles subpictus (Yapabandara \& Curtis, 2004), Anopheles gambiae (Mbare et al., 2013), Bradysia coprophila (Ludwig \& Oetting, 2001), Lycoriella ingenue (Erler et al., 2011) and Culex pipiens (Al-Sarar et al., 2011). Singh \& Kumar (2015) also report a decrease in adult emergence, formation of pupal-adult mosaics and the development of deformed adults in the F1 generation of Sarcophaga ruficornis after topically applying pyriproxyfen to the parental generation.

In the current experiments, pyriproxyfen also prolonged pupal development at the highest dose $\left(\mathrm{ID}_{50}\right)$ compared

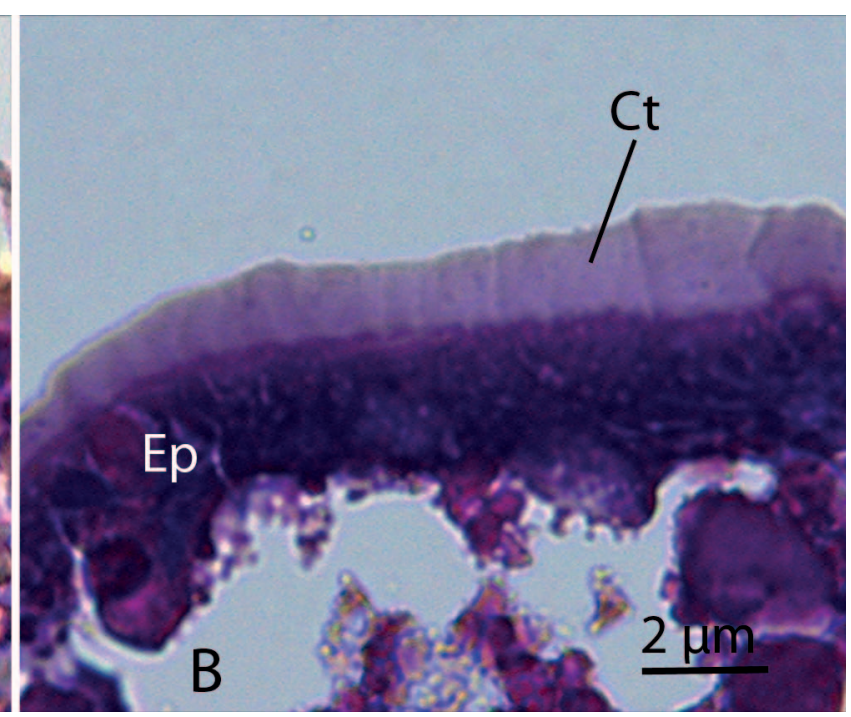

Fig. 6. Effect of pyriproxyfen $\left(\mathrm{ID}_{50}\right)$, topically applied to larvae of $D$. melanogaster at the end of the third instar. A - control: new adult cuticle with a normal bristles; $\mathrm{B}$ - treated: new cuticle with no bristles. $\mathrm{Ct}$ - cuticle; $\mathrm{Ep}$ - epidermis; $\mathrm{Br}$ - bristles. 
to the controls, which indicates that the $\mathrm{JH}$ analog (here pyriproxyfen) can induce delays in the development of the pupal-adult transition. Alizadeh et al. (2012) previously reported that the larvae and pupae of Plutella xylostella treated with pyriproxyfen take longer to complete their development. Similar effects are reported by Singh \& Kumar (2011) for Papilio demoleus treated with pyriproxyfen. Hamaidia \& Soltani (2014) also report an increase in the duration of the larval and pupal stages of Culex pipiens treated with Kinoprene, another JHA.

At the beginning of the pupal stage there is JH sensitive period when JH must be absent in epidermal cells for successful adult development (Nijhout, 1994). Hence, the presence of pyriproxyfen at these critical times resulted in a prolonged pupal development, deformed adults and reduction in adult emergence.

In D. melanogaster, metamorphosis is controlled by several pulses of $20 \mathrm{E}$ secretion, the first occurs at the end of the third instar larva, when the $\mathrm{JH}$ titer is very low and initiates pupararium formation, the second $12 \mathrm{~h}$ after puparium formation (APF) triggering pupation, and finally the onset of adult development requires a large wave beginning approximately $30 \mathrm{~h} \mathrm{APF}$ in the total absence of JH (Handler, 1982; Riddiford, 1993). In the present study we demonstrated that pyriproxyfen applied at the end of last larval instar significantly reduced the ecdysteroid titer during the pupal stage by inhibiting the production of $20 \mathrm{E}$. Negative effects of JHA on ecdysteroid titers are reported in different orders of insects, especially Lepidoptera and Coleoptera. Aribi et al. (2006) report that pyriproxyfen reduces, in a dose-dependent manner, the ecdysteroid titer in the hemolymph of Tenebrio molitor pupae. Similar effects are recorded for other JHA, like methoprene and fenoxycarb, on the larval stages of the Coleoptera, Tribolium freemani (Hirashima et al., 1995) and Zophobas atratus (Aribi et al., 1999), Lepidoptera, Bombyx mori (Monconduit et al., 1998) and Omphisa fuscidentalis (Singtriopo et al., 2002) and the adult stage of D. melanogaster (Diptera) (Handler, 1982). Indeed, one of the many vital functions of $\mathrm{JH}$ in insect development is to modulate the action of the molting hormone (20E) and coordinate insect moulting and metamorphosis (Riddiford, 2008). Moreover, Yamanaka et al. (2007) demonstrate the direct effect of JH on the prothoracic gland during ecdysterodogenesis.

Chitin has an important role in insect development and its synthesis and degradation must be tightly regulated. Our results indicate that only the highest dose $\left(\mathrm{ID}_{50}\right)$ of pyriproxyfen significantly increased the chitin content of pupae of D. melanogaster compared to the control. It is reported that the molting hormone $20 \mathrm{E}$ regulates chitin metabolism by stimulating the secretion and activity of enzymes (Mezendorfer \& Zimoch, 2003). Both the secretion and activation of chitinolytic enzymes are clearly controlled by ecdysteroids (Reynolds \& Samuels, 1996). In addition, Kimura (1973) showed many years ago that the activity of enzymes in the molting fluid can be stimulated by injecting ecdysteroid. More recently, Nasr et al. (2010) report an inhibition of chitinase activity in larvae of Spodoptera littoralis treated with pyriproxyfen. Indeed, the expression of the gene determining the production of chitinolytic enzymes, which is normally induced by ecdysteroids, is suppressed by juvenile hormone (Cohen, 2010). In Manduca sexta expression of chitinase genes is suppressed by the topical application of the juvenile hormone mimic, fenoxycard (Kramer et al., 1993; Zen et al., 1996). The increase in chitin content recorded in our experiments may be related to an inhibition of chitinase activity due to the reduction in the secretion of ecdysteroids recorded following treatment with pyriproxyfen.

The histological study revealed that pyriproxyfen affects the secretion of the adult cuticle resulting in an increase in the thickness of the new cuticle and suppression of the development of bristles. The stimulation of the secretion of the adult cuticle by JHA is reported by Dedos \& Fugo (2001) in B. mori treated with fenoxycarb. The increase in cuticle thickness recorded in our experiments seems to be correlated with the increase in chitin content, which is an important constituent of cuticles. Moreover, it is reported that in D. melanogaster the application of JH or JHA during the final larval instar or at pupariation causes the formation of a pupal-adult mosaic, with a transparent abdomen covered with pupal cuticle, with no or a few bristles (Zhou \& Riddifrod, 2002). Indeed, the status quo action of $\mathrm{JH}$ on the pupal-adult transformation is mediated by the $\mathrm{JH}$-induced re-expression of the broad (br) gene during adult differentiation causing the formation of a second pupal cuticle (Zhou \& Riddifrod, 2002; Jindra et al., 2013). $\mathrm{Br}$ can both activate pupal genes and suppress adult genes, thus, during the crucial period of the commitment to adult development, ecdysone in the absence of $\mathrm{JH}$ switches off $\mathrm{Br}$ so that the adult-specific program of differentiation can occur (Goodman \& Granger, 2005). The presence of JH (here pyriproxyfen) at this critical period may interfere with ecdysone and account for the abnormalities in cuticle structure and inhibition of adult emergence recorded in $D$. melanogaster. Furthermore, as the cuticle of insects is an effective barrier to the evaporation of water (Gibbs, 2011), the increase in cuticle thickness recorded when treated with pyriproxyfen may act as potential protective system against hot temperatures and desiccation, especially in the context of global warming.

In conclusion, our findings indicate that pyriproxyfen negatively affects the hormonal control of metamorphosis causing perturbations in D. melanogaster development. Nevertheless, the precise way in which ecdysone is affected by pyriproxyfen requires further research. Moreover, information is needed on the sublethal effects of pyriproxyfen on their offspring.

ACKNOWLEDGEMENTS. Thanks are due to G.L. Rezende, Instituto Oswaldo Cruz, Fiocruz, Rio de Janeiro, Brazil, for his detailed protocol for chitin quantification. This research was supported by the National Fund for Scientific Research in Algeria (Laboratory of Applied Animal Biology to N. Soltani), by the Ministry of Higher Education and Scientific Research of Algeria (CNEPRU project F 011.2008. 0024 to N. Aribi). 


\section{REFERENCES}

Аввотт W.S. 1925: A method of computing the effectiveness of an insecticide. - J. Econ. Entomol. 18: 265-267.

Alizadeh M., Karimzadeh J., Rassoulian G.H., Farazmand H., Hoseini-Naveh V. \& Pourian H.R. 2012: Sublethal effects of pyriproxyfen, a juvenile hormone analogue, on Plutella xylostella (Lepidoptera: Plutellidae): life table study. - Arch. Phytopathol. Pfl. 45: 1741-1763.

Al-Sarar A.S., Al-Shahrani D., Bayoumi A.E., Abobakr Y. \& Hussein H.I. 2011: Laboratory and field evaluation of some chemical and biological larvicides against Culex spp. (Diptera: Culicidae) immature stages. - Int. J. Agric. Biol. 13: 115-119.

Aribi N., Quennedey A., Soltani N. \& Delbecque J.P. 1999: L'initiation de la métamorphose chez Zophobas atratus: (Coleoptera: Tenebrionidae): effects des ligatures et des régulateurs de croissance. - Ann. Soc. Entomol. Fr. 35: 59-64.

Aribi N., Smagghe G., Lakbar C., Soltani-Mazouni N. \& Soltani N. 2006: Effect of pyriproxyfen a juvenile hormone analogue, on development of the mealworm, Tenebrio molitor. - Pestic. Biochem. Phys. 84: 55-62.

Boina D.R., Rogers M.E., Wang N. \& Stelinski L. 2009: Effect of pyriproxyfen, a juvenile hormone mimic, on egg hatch, nymph development, adult emergence and reproduction of the Asian citrus psyllid, Diaphorina citri Kuwayama. - Pest Manag. Sci. 66: 349-357.

CoHen E. 2010: Chitin biochemistry: synthesis, hydrolysis and inhibition. - Adv. Insect Physiol. 38: 5-74.

Dedos S.G. \& Fugo H. 2001: Acceleration of pupal-adult development by fenoxycarb in the silkworm, Bombyx mori. - Zool. Sci. 18: 771-777.

De Loof A., Vandersmissen T., Marchal E. \& Schoofs L. 2015 Initiation of metamorphosis and control of ecdysteroid biosynthesisin insects: The interplay of absence of juvenile hormone, PTTH, and $\mathrm{Ca}^{2+}$ - homeostasis. - Peptides 68: 120-129.

Dubrovsky E.B. 2005: Hormonal cross talk in insect development. - Trends Endocrinol. Metab. 16: 6-11.

Erler F., Polat E., Demir H., Catal M. \& Tuna G. 2011: Control of mushroom sciarid fly Lycoriella ingenua populations with insect growth regulators applied by soil drench. - J. Econ. Entomol. 104: 839-844.

Farnesi L.C., Brito J.M., Linss J.G., Pelajo-Machado M., Valle D. \& Rezende G.L. 2012: Physiological and morphological aspects of Aedes aegypti developing larvae: Effects of the chitin synthesis inhibitor novaluron. - PLOS ONE 7(1): e30363.

Ghasemi A., Sendi J.J. \& Ghadamyari M. 2010: Physiological and biochemical effect of pyriproxyfen on Indian meal moth Plodia interpunctella (Hübner) (Lepidoptera: Pyralidae). - J. Plant Protect. Res. 50: 416-422.

GibBs A.G. 2011: Thermodynamics of cuticular transpiration. J. Insect Physiol. 57: 1066-1069.

Goodman W.G. \& Granger N.A. 2005: The juvenile hormones In Gilbert L.I., Iatrou K. \& Gill S.S. (eds): Comprehensive Molecular Insect Science Endocrinology. Vol. 3. Elsevier, Oxford, pp. 319-408.

HAMAIDIA K. \& Soltani N. 2014: Laboratory evaluation of a biorational insecticide, kinoprene, against Culex pipiens larvae: Effects on growth and development. - Annu. Res. Rev. Biol. 4: 2263-2273.

HANDLER A.M. 1982: Ecdysteroid titers during pupal and adult development in Drosophila melanogaster. - Dev. Biol. 93: $73-82$.

Harburger L., Beltrán G., Goldberg L., Goldberg L., Zerba E., Licastro S. \& Masuh H. 2011: A new strategy for Aedes aegypti (Diptera: Culicidae) control with community participa- tion using a new fumigant formulation. - J. Med. Entomol. 48: $577-583$.

Hatakoshi M. 2012: Pyriproxyfen: a new juvenoid. In Kramer W., Schirmer U., Jeschke P. \& Witschel M. (eds): Modern Crop Compound. 2nd ed. Wiley-VCH, Weinheim, pp. 963-998.

Hirashima A., Takeya R., Tanigushi E. \& Eto M. 1995: Metamorphosis, activity of juvenile hormone esterase and alteration of ecdysteroids titres: effects of larval density and various stress on the red flour beetle Tribolium freemani Hinton (Coleoptera, Tenebrionidae). - J. Insect Physiol. 41: 383-388.

IshaAya I., De Cock A. \& Degheele D. 1994: Pyriproxyfen, a potent suppressor of egg hatch and adult formation of the greenhouse whitefly (Homoptera: Aleyrodidae). - J. Econ. Entomol. 87: 1185-1189.

JindRA M., PALLi S.R. \& RidDIFORd L.M. 2013: The juvenile hormone signaling pathway in insect development. - Annu. Rev. Entomol. 58: 181-204.

Kawada H., Dohara K. \& Shinjo G. 1988: Laboratory and field evaluation of an insect growth regulator, 4-phenoxyphenyl (RS)-2-(2-pyridy1oxy) propyl ether, as a mosquito larvicide. - Jpn. J. Sanit. Zool. 39: 339-346.

KIMURA S. 1973: The control of chitinase activity by ecdysterone in larvae of Bombyx mori. - J. Insect Physiol. 19: 115-123.

Kramer K.J., Corpuz L., Choi H.K. \& Muthukrishnan S. 1993: Sequence of a cDNA and expression of the gene encoding epidermal and gut chitinases of Manduca sexta. - Insect Biochem. Mol. Biol. 23: 691-701.

Ludwig S.W. \& Oetring R.D. 2001: Evaluation of medium treatments for management of Frankliniella occidentalis (Thripidae: Thysanoptera) and Bradysia coprophila (Diptera: Sciaridae). - Pest Manag. Sci. 57: 1114-1118.

Martoja R. \& Martoja M. 1967: Initiation aux Techniques de l'Histologie Animale. Masson, Paris, 345 pp.

Mbare O., Lindsay S.W. \& Fillinger U. 2013: Dose-response tests and semi-field evaluation of lethal and sub-lethal effects of slow release pyriproxyfen granules $\left(\operatorname{Sumilarv}^{\circledR} 0.5 \mathrm{G}\right)$ for the control of the malaria vectors Anopheles gambiae sensu lato. - Malaria J. 12: 94.

MERZENDORFER H. \& Zimoch L. 2003: Chitin metabolism in insects: structure, function and regulation of chitin synthases and chitinases. - J. Exp. Biol. 206: 4393-4412.

Miyamoto J., Hirano M., Takimoto Y. \& Hatakoshi M. 1993: Insect growth regulators for pest control, with emphasis on juvenile hormone analogs: Present status and future prosrects. In Duke S.O., Menn J.J. \& Plimmer J.R. (eds): Pest Control with Enhanced Environmental Safety, American Chemical Society Symp., Washington, DC, pp. 144-168.

Moadeli T., Hejazi M.J. \& Golmohammadi G. 2014: Lethal effects of pyriproxyfen, spinosad, and indoxacarb and sublethal effects of pyriproxyfen on the $1^{\text {st }}$ instar larvae of beet armyworm, Spodoptera exigua Hübner (Lepidoptera: Noctuidae) in the laboratory. - J. Agric. Sci. Tech. 16: 178-189.

Monconduit H. \& MaUchamp B. 1998: Effects of ultralow doses of fenoxycarb on juvenile hormone-regulated physiological parameters in the silkworm, Bombyx mori L. - Arch. Insect Biochem. Physiol. 37: 178-189.

NasR H.M., BADawy M. \& Rabea E.I. 2010: Toxicity and biochemical study of two insect growth regulators, buprofezin and pyriproxyfen, on cotton leafworm Spodoptera littoralis. Pestic. Biochem. Phys. 98: 198-205.

Nishout H.F. 1994: Insect Hormones. Princeton University Press, Princeton, NJ, 280 pp.

Ohba S., Ohashi K., Pujiyati E., Higa Y., Kawada H., Mito N. \& TAKAGI M. 2013: The effect of pyriproxyfen as a "population 
growth regulator" against Aedes albopictus under semi-field conditions. - PLoS ONE 8(7): e67045.

Pener M.P. \& Dhadialla T.S. 2012: An overview of insect growth disruptors; applied aspects. - Adv. Insect Physiol. 43: 1-162.

Quinn L., Lin J., Cranna N., Lee J., Mitchell N. \& Hannan R. 2012: Steroid hormones in Drosophila: How ecdysone coordinates developmental signalling with cell growth and division. In Abduljabbar H. (ed.): Steroids - Basic Science. InTech, Rijeka, pp. 141-168.

Ramaseshadri P., Farkaš R. \& Palli S.R. 2012: Recent progress in juvenile hormone analogs (JHA) research. - Adv. Insect Physiol. 43: 353-436.

Reynolds S.E. \& SAmuels R.I. 1996: Physiology and biochemistry of insect moulting fluid. - Adv. Insect Physiol. 26: 157232.

RidDIFORD L.M. 1993: Hormones and Drosophila development. In Bate M. \& Martinez Arias A. (eds): The Development of Drosophila melanogaster. Cold Spring Harbor Laboratory Press, NY, pp. 899-939.

RIDDIFORD L.M. 1996: Molecular aspects of juvenile hormone action in insect metamorphosis. In Gilbert L.I., Tata J.R. \& Atkinson B.G. (eds): Metamorphosis: Postembryonic Reprogramming of Gene Expression in Amphibian and Insect Cells. Academic Press, San Diego, pp. 223-251.

RIDDIFORD L.M. 2008: Juvenile hormone action: a 2007 perspective. - J. Insect Physiol. 54: 895-901.

Riddiford L.M., Hiruma K., Zhou X. \& Nelson C.A. 2003: Insights into the molecular basis of the hormonal control of molting and metamorphosis from Manduca sexta and Drosophila melanogaster. - Insect Biochem. Mol. Biol. 33: 1327-1338.

Sazo L., Araya J.E. \& Esparza S. 2008: Control of San Jose scale nymphs, Diaspidiotus perniciosus (Comstock), on almond and apple orchards with pyriproxyfen, phenoxycarb, chlorpyrifos, and mineral oil. - Chil. J. Agric. Res. 68: 284-289.

Sihuincha M., Zamora-Perea E., Orellana-Rios W., Stancil J.D., López-Sifuentes V., Vidal-Oré C. \& Devine G.J. 2005: Potential use of pyriproxyfen for control of Aedes aegypti (Diptera: Culicidae) in Iquitos, Perú. - J. Med. Entomol. 42: 620-630.
Singh S. \& Kumar K. 2011: Diofenolan: a novel insect growth regulator in common citrus butterfly, Papilio demoleus. Phytoparasitica 39: 205-213.

SinGH S. \& Kumar K. 2015: Effects of juvenoid pyriproxyfen on reproduction and F1 progeny in myiasis causing flesh fly Sarcophaga ruficornis L. (Sarcophagidae: Diptera). - Parasitol. Res. 114: 2325-2331.

Singtripop T., Oda Y., Wanichacheewa S. \& SakURai S. 2002: Sensitivities to juvenile hormone and ecdysteroid in the diapauses larvae of Omphisa fuscidentalis based on the hemolymph trehalose dynamics index. - J. Insect Physiol. 48: 817-824.

WHO 2008: Guidelines for Drinking-Water Quality. 3rd ed. World Health Organization, Geneva, 668 pp.

Yamanaka N., Honda N., Osato N., Niwa R., Mizoguchi A. \& KATAOKA H. 2007: Differential regulation of ecdysteroidogenic P450 gene expression in the silkworm, Bombyx mori. - Biosci. Biotech. Bioch. 71: 2808-2814.

Yamanaka N., Rewitz K. \& O’Connor M.B. 2013: Ecdysone control of developmental transitions: Lesson from Drosophila research. - Annu. Rev. Entomol. 58: 497-516.

YAPABANDARA A.M.G.M. \& CURTIS C.F. 2004: Control of vectors and incidence of malaria in an irrigated settlement scheme in Sri Lanka by using the insect growth regulator pyriproxyfen. - J. Am. Mosq. Contr. Assoc. 20: 395-400.

Zen K.C., Choi H.K., Krishnamachary N., Muthukrishnan S. \& KRAMER K.J. 1996: Cloning, expression, and hormonal regulation of an insect beta- $\mathrm{N}$ acetylglucosaminidase gene. - Insect Biochem. Mol. Biol. 26: 435-444.

ZHou X. \& Riddiford L.M. 2002: Broad-Complex specifies pupal development and mediates the prevention of the pupal-adult transformation by juvenile hormone in Drosophila and Manduca. - Development 129: 2259-2269.

ZHOU X. \& RIDDIFORD L.M. 2008: rosy function is required for juvenile hormone effects in Drosophila melanogaster. - Genetics 178: 273-281.

Received March 28, 2015; revised and accepted May 14, 2015 Prepublished online July 21,2015 